\title{
EXPERIMENTAL STUDY ON VIBRATION BEHAVIOR OF COLD-FORM STEEL CONCRETE COMPOSITE FLOOR
}

\author{
Xuhong Zhou ${ }^{1,2}$, Yongjun $\mathrm{He}^{1, *}$, Ziwen $\mathrm{Jia}^{3}$ and Shaofeng $\mathrm{Nie}^{4}$ \\ ${ }^{1}$ Professor, College of Civil Engineering, Hunan University, Changsha, 410082, PR China \\ ${ }^{2}$ Professor, Lanzhou University, Lanzhou, 730000, PR China \\ ${ }^{3}$ Graduate, ${ }^{4}$ Lecturer, Chang'an University, Xi'an, 710064, PR China \\ *(Corresponding author : E-mail: hyj0087@163.com)
}

Received:23 December 2010; Revised: 28 February 2011; Accepted: 11 March 2011

\begin{abstract}
This paper introduces the experimental study on vibration behavior of 4 full scale cold-formed steel composite floors. The research is focused on the fundamental frequency of composite floor, which considering the influence of screw spacing and rigid blocking under different loading cases during normal use. The test apparatus and test methods are introduced in details. Then, the finite element analysis model of cold-formed steel composite floors is set up to study the vibration behavior. Finite element analysis results in this paper are close to those of the experiments. The results of the tests and finite element analysis show that the flexural rigidity of composite floor can be improved by changing the spacing of screws. The fundamental frequency of composite floor with large spacing of screws, that connect profiled steel sheet and the flange of joists, is smaller than the composite floor with small screw spacing. The lateral stability of joists can be strengthened; the flexural rigidity and frequency of composite floor can be increased by setting rigid blocking at mid-span of the adjacent joist of the composite floor. The fundamental frequency of composite floor increases if the end restraints are enhanced. It is suggested that the fundamental frequency of cold-formed steel concrete composite floor should be more than $10 \mathrm{~Hz}$.
\end{abstract}

Keywords: Composite floor, Cold-formed steel, Fundamental frequency, Experimental study, Finite element analysis

\section{INTRODUCTION}

Vibrations caused by human activities have long been recognized as a major serviceability concern for residential floor systems. Cold-formed steel composite steel concrete slab residential floor systems provide an alternative for traditional wood residential floor systems. Steel framed floors are lighter, with high-strength and have less damping than traditional wood floors. However, lightweight floors will be more easily to vibrate under human activities, such as walking, running and jumping. The research on vibration behavior of cold-formed steel concretes composite floor due to walking in light-frame construction is carried out in this paper. Several acceptability criteria have been developed for such kinds of floor systems based on the static deflection of the floors. Onysko's criterion (CWC [1]) is based on the results of an extensive field study conducted in Canada. The survey involved the assessment of perceived acceptability of 646 floors in five cities of all types of wood construction. Great care was taken to obtain the subjective evaluation of the suitability of the floor from the homeowner, not the vibration performance. The study showed that the dynamic response due to an impact load and the deflection due to a static concentrated load were the two parameters that best correlated with perceived acceptability. In conjunction with a consortium of timber researchers and engineers, he has proposed a new design procedure for limiting vibrations of timber floors in the design stage. The method results in a value for span length, calculated from the fundamental properties of the floor and construction variables (i.e. sub-flooring type, glued or fastened flooring, spacing and bridging), which satisfies the deflection criterion. ATC Design Guide suggests the natural frequency of light-frame floor should be greater than $8 \mathrm{~Hz}$ (ATC [2]). If the natural frequency is less than $8 \mathrm{~Hz}$, resonance occurs, the floor deflection under a point load of $1.0 \mathrm{kN}$ remains less than $2.0 \mathrm{~mm}$. Ohlsson's Criterion is applicable to all floor constructions (material independent) which have a lowest resonance frequency greater than $8 \mathrm{~Hz}$ (Ohlsson [3]). However, use of the method is limited to lightweight floors with span lengths less 
than 6-8 meters. Resonance frequencies for a floor system are calculated assuming a simply supported rectangular orthotropic plate and have not taken into account composite behavior between the joists and flooring. This criterion also requires a check on the static deflection. The deflection of this single joist in a floor system is to be limited to $1.5 \mathrm{~mm}$ under the action of a $1.0 \mathrm{kN}$ static concentrated load. The second requirement is a check on the response to an impulse load of 1.0N-s. The Australian Standard Domestic Metal Framing Code (AS3623 [4]) was developed for residential steel framed construction and uses much of the criterion proposed by Ohlsson. The dynamic serviceability requirements provided in this Code are limited to floors with a lowest natural frequency greater than $8 \mathrm{~Hz}$. Two requirements are be used to assess the dynamic performance of a steel framed floor system. The first requires that under the application of a static concentrated load of $1.0 \mathrm{kN}$ anywhere on the floor, the floor deflection shall not exceed $2.0 \mathrm{~mm}$. The second requirement is likely to control in the design of long span floors, but guidance is not given as to what span lengths correspond to long span floors. Johnson [5] developed a design criterion for timber floors based on the results of 86 in-situ floors under construction. Johnson proposed that the fundamental frequency be greater than $15 \mathrm{~Hz}$ for a floor supporting only its own weight. Typically, the fundamental frequency is calculated from a single joist in the floor system. However, if a girder is contributing to the response of the floor, the system frequency is taken as the fundamental frequency. In addition, Xu [6], and Kraus [7] put forward a different construction method to the floor frequency's effects. In this paper, an experimental study on vibration behavior of 4 full-scale cold-formed steel composite floors is carried out. The research of the fundamental frequency of composite floor, which considering the influence of screw space and rigid blocking under different loading cases during normal use is carried out in this paper. Then, a finite element analysis model of cold-formed steel composite floors is presented to study their vibration behavior.

\section{SUMMARY OF TEST}

\subsection{Construction Details}

The cold-formed steel composite floor is composed of cold-formed steel and sheeting-concrete composite slabs as shown in Figure 1. The joists of the floor are cold-formed steel with $\mathrm{C}$ section, and connecting with the boundary beams, which have $U$ section, by self drilling screws through blocking. The spacing of the joists, which parallel to the wall studs, is $400 \mathrm{~mm}$ or $600 \mathrm{~mm}$.

\subsection{Specimens Design}

Four composite floors, with consideration in the different spacing of self-drilling screws and the existence of the blockings, are designed in this paper (Figures 2 and 3). The specimens FL-1 and FL-2 have the same screw space type A as shown in Table 1. The difference of FL-1 and FL-2 is that there are rigid blocking between the joists in FL-2 and none in FL-1. The specimens FL-3 and FL-4 have the same screw space type B as shown in Table 1. And the difference of FL-3 and FL-4 is that there are rigid blockings between the joists in FL-4 but none in FL-3. The research on the fundamental frequency of composite floor, which considers the influence of screw spacing and rigid blocking under different loading cases during normal use, is carried out. The configurations of the specimens are described in Table 1. 


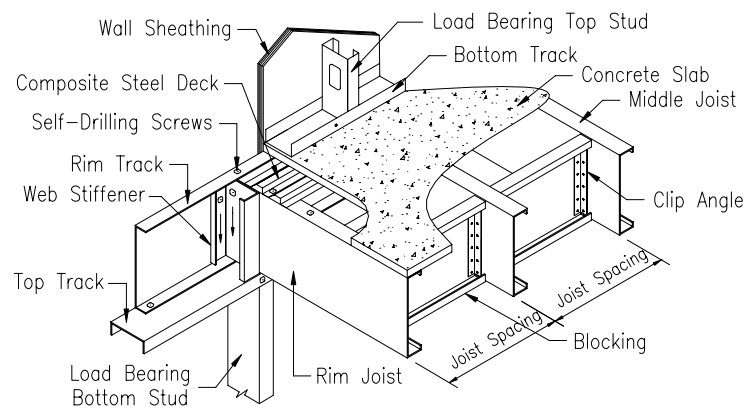

Figure 1. Details of Composite Floor

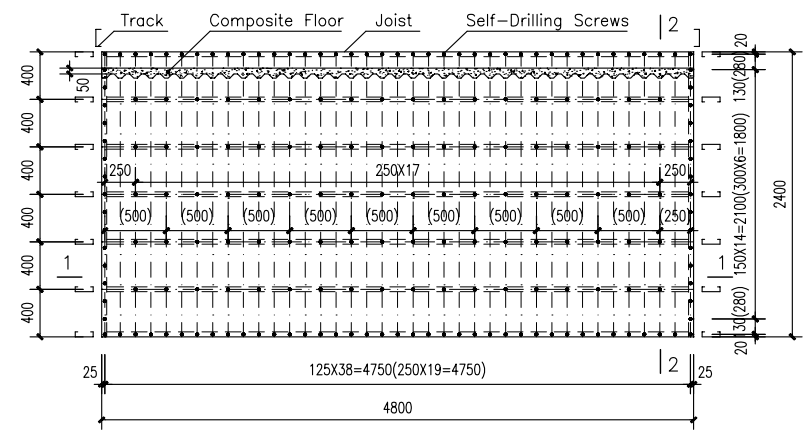

(a)

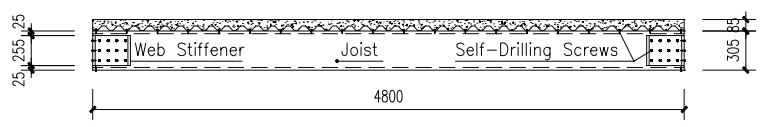

(b)

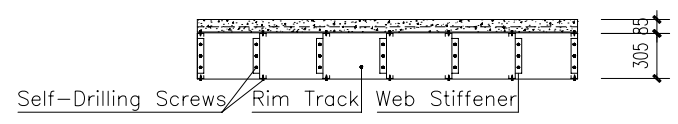

(c)

Figure 2. Construction Details of FL - 1(3):

(a) Layout Chart (The Data in the Bracket belong to FL-3); (b) Section 1-1; (c) Section 2-2

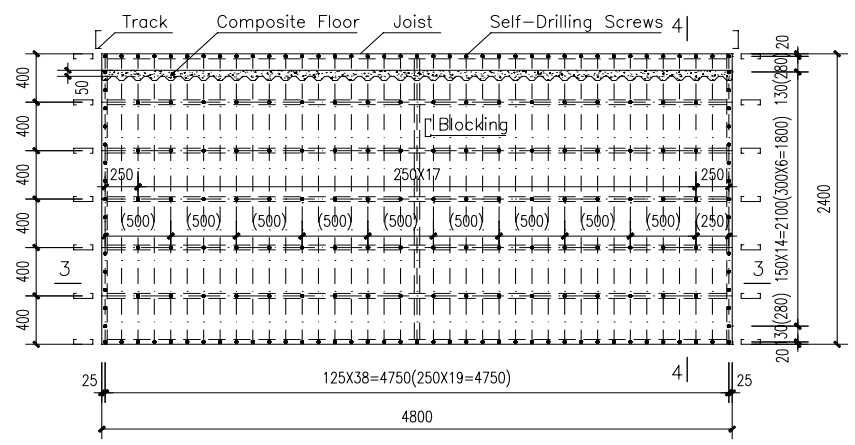

(a)

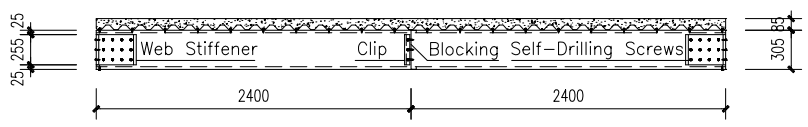

(b)

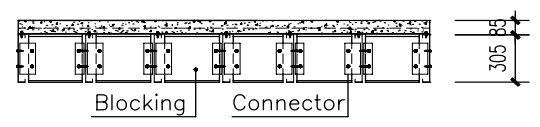

(c)

Figure 3. Construction Details of FL - 2(4):

(a) Layout Chart (The Data in the Bracket belong to FL-4); (b) Section 3-3; (c) Section 4-4 
Table 1. Configuration of Specimens

\begin{tabular}{|c|c|c|c|c|c|}
\hline SPECIMENS & LOAD CASES & $\begin{array}{l}\text { SCREW SPACE } \\
/ \mathrm{mm}\end{array}$ & BLOCKING & $\begin{array}{c}\text { LIVE } \\
\text { LOAD } \\
\text { / N/MM } \\
\end{array}$ & $\begin{array}{l}\text { BEARING } \\
\text { SUPPORT }\end{array}$ \\
\hline \multirow{6}{*}{ FL-1 } & FL-1-A-1-A-0.0 & \multirow{12}{*}{$\begin{array}{l}\text { A: } 150 \mathrm{~mm} \text { along } \\
\text { the direction of } \\
\text { tracks, } 125 \mathrm{~mm} \text { at } \\
\text { the side joists } \\
\text { and } 250 \mathrm{~mm} \text { in } \\
\text { the middle field } \\
\text { of floor }\end{array}$} & \multirow{6}{*}{ A: No } & 0.0 & \multirow{3}{*}{ 1: Simple support } \\
\hline & FL-1-A -1-A-0.8 & & & 0.8 & \\
\hline & FL-1-A -1-A-2.0 & & & 2.0 & \\
\hline & FL-1-A -2-A-0.0 & & & 0.0 & \multirow{3}{*}{ 2: Fix support } \\
\hline & FL-1-A -2-A-0.8 & & & 0.8 & \\
\hline & FL-1-A -2-A-2.0 & & & 2.0 & \\
\hline \multirow{6}{*}{ FL-2 } & FL-2-A -1-B-0.0 & & \multirow{6}{*}{ B: Yes } & 0.0 & \multirow{3}{*}{ 1: Simple support } \\
\hline & FL-2-A -1-B-0.8 & & & 0.8 & \\
\hline & FL-2-A -1-B-2.0 & & & 2.0 & \\
\hline & FL-2-A -2-B-0.0 & & & 0.0 & \multirow{3}{*}{ 2: Fix support } \\
\hline & FL-2-A -2-B-0.8 & & & 0.8 & \\
\hline & FL-2-A -2-B-2.0 & & & 2.0 & \\
\hline \multirow{6}{*}{ FL-3 } & FL-3-B -1-A-0.0 & \multirow{12}{*}{$\begin{array}{l}\text { B: } 300 \mathrm{~mm} \text { along } \\
\text { the direction of } \\
\text { tracks, } 250 \mathrm{~mm} \text { at } \\
\text { the side joists } \\
\text { and } 500 \mathrm{~mm} \text { in } \\
\text { the middle field } \\
\text { of floor }\end{array}$} & \multirow{6}{*}{ A: No } & 0.0 & \multirow{3}{*}{ 1: Simple support } \\
\hline & FL-3-B -1-A-0.8 & & & 0.8 & \\
\hline & FL-3-B -1-A-2.0 & & & 2.0 & \\
\hline & FL-3-B -2-A-0.0 & & & 0.0 & \multirow{3}{*}{ 2: Fix support } \\
\hline & FL-3-B -2-A-0.8 & & & 0.8 & \\
\hline & FL-3-B -2-A-2.0 & & & 2.0 & \\
\hline \multirow{6}{*}{ FL-4 } & FL-4-B -1-B-0.0 & & \multirow{6}{*}{ B: Yes } & 0.0 & \multirow{3}{*}{ 1: Simple support } \\
\hline & FL-4-B -1-B-0.8 & & & 0.8 & \\
\hline & FL-4-B -1-B-2.0 & & & 2.0 & \\
\hline & FL-4-B -2-B-0.0 & & & 0.0 & \multirow{3}{*}{ 2: Fix support } \\
\hline & FL-4-B -2-B-0.8 & & & 0.8 & \\
\hline & FL-4-B -2-B-2.0 & & & 2.0 & \\
\hline
\end{tabular}

Note: FL-1-A-1-A-0.0 denotes floor specimen_FL-1, Screw spacing A, Bearing support 1, Blocking A, Live load 0.0 $\mathrm{N} / \mathrm{mm}^{2}$.

The framework of the composite floor is composed of 7 joists (C305 $\times 41 \times 14 \times 1.6 \mathrm{~mm})$ and 2 tracks (U307 $\times 35 \times 1.6 \mathrm{~mm}$ ). The length of each joist is $4800 \mathrm{~mm}$, and that of track is $2400 \mathrm{~mm}$. The spacing of the joists is $400 \mathrm{~mm}$. The section of the seat blocking, which connects the web of joist and track by self-drilling screws, is C305 $\times 41 \times 14 \times 1.6 \mathrm{~mm}$ with a length of $255 \mathrm{~mm}$. The section of blocking is C305 $\times 41 \times 14 \times 1.6 \mathrm{~mm}$ and with a length of $380 \mathrm{~mm}$. The connectors are self-drilling screws and their numbers and arrangements are determined according to the Standard of China (JG/T 182-2005 [8]). The sheeting-concrete composite slabs are composed of profiled steel sheet and concrete with grade C30, whose thickness is $0.74 \mathrm{~mm}$ and $50 \mathrm{~mm}$, respectively. The rib of slab is vertical to the joist, and connects to the flange of joist with self-drilling screws (4816). There are no shear resistance studs and reinforcing steel bars between the steel sheets and concrete.

According to the material experiments, it is known that the material properties of the specimens are as follows. the yielding strength of the cold-formed steel is $330.4 \mathrm{~N} / \mathrm{mm}^{2}$, Young's modulus is $2.17 \times 10^{5} \mathrm{~N} / \mathrm{mm}^{2}$, passion ratio is 0.3 ; and the yielding strength of the steel slabs is $382.43 \mathrm{~N} / \mathrm{mm}^{2}$, Young's modulus is $2.06 \times 10^{5} \mathrm{~N} / \mathrm{mm}^{2}$, passion ratio is 0.3 ; the standard compression strength of concrete is $23.9 \mathrm{~N} / \mathrm{mm}^{2}$, Young's modulus is $3.0 \times 10^{4} \mathrm{~N} / \mathrm{mm}^{2}$, passion ratio is 0.2 .

The dimensions and loading cases of specimens are shown in Table 2. According to Loading Code for the Design of Building Structures (GB 50009-2001 [9]), $2.0 \mathrm{kN} / \mathrm{m}^{2}$ is adopted as the live load in this paper; quasi-permanent value of the variable load is $0.8 \mathrm{kN} / \mathrm{m}^{2}$ and $0.0 \mathrm{kN} / \mathrm{m}^{2}$ when no live load is considered. 
Table 2. Dimension of Specimens and the Comparisons of Test Results and Numerical Results

\begin{tabular}{|c|c|c|c|c|c|c|c|}
\hline SPECIMENS & LOAD CASES & $\begin{array}{c}\text { LENGTH } \\
/ \mathrm{MM}\end{array}$ & $\begin{array}{l}\text { WIDTH } \\
\text { /MM }\end{array}$ & $\begin{array}{c}\text { THICKNESS } \\
\text { /MM }\end{array}$ & $\begin{array}{c}\text { TEST } \\
\text { FREQUENCY } \\
/ \mathrm{Hz} \\
\end{array}$ & $\begin{array}{c}\text { FEM } \\
\text { FREQUENCY } \\
/ \mathrm{Hz} \\
\end{array}$ & $\begin{array}{c}\text { FEM } \\
\text { /TEST }\end{array}$ \\
\hline \multirow{6}{*}{ FL-1 } & FL-1-A-1-A-0.0 & \multirow{6}{*}{4800} & \multirow{6}{*}{2400} & \multirow{6}{*}{50} & 12.4 & 12.35 & 1.00 \\
\hline & FL-1-A -1-A-0.8 & & & & 11.3 & 11.60 & 1.03 \\
\hline & FL-1-A -1-A-2.0 & & & & 10.4 & 10.02 & 0.96 \\
\hline & FL-1-A -2-A-0.0 & & & & 12.8 & 12.50 & 0.98 \\
\hline & FL-1-A -2-A-0.8 & & & & 11.8 & 12.25 & 1.04 \\
\hline & FL-1-A -2-A-2.0 & & & & 11.3 & 11.64 & 1.03 \\
\hline \multirow{6}{*}{ FL-2 } & FL-2-A -1-B-0.0 & \multirow{6}{*}{4800} & \multirow{6}{*}{2400} & \multirow{6}{*}{50} & 12.3 & 13.56 & 1.10 \\
\hline & FL-2-A -1-B-0.8 & & & & 11.3 & 12.08 & 1.07 \\
\hline & FL-2-A -1-B-2.0 & & & & 10.5 & 10.15 & 0.97 \\
\hline & FL-2-A -2-B-0.0 & & & & 12.5 & 13.76 & 1.10 \\
\hline & FL-2-A -2-B-0.8 & & & & 12.8 & 13.53 & 1.06 \\
\hline & FL-2-A -2-B-2.0 & & & & 11.5 & 12.55 & 1.09 \\
\hline \multirow{6}{*}{ FL-3 } & FL-3-B -1-A-0.0 & \multirow{6}{*}{4800} & \multirow{6}{*}{2400} & \multirow{6}{*}{52} & 13.2 & 11.96 & 0.91 \\
\hline & FL-3-B -1-A-0.8 & & & & 12.2 & 11.32 & 0.93 \\
\hline & FL-3-B -1-A-2.0 & & & & 11.3 & 9.84 & 0.87 \\
\hline & FL-3-B -2-A-0.0 & & & & 13.8 & 12.05 & 0.87 \\
\hline & FL-3-B -2-A-0.8 & & & & 12.5 & 11.84 & 0.95 \\
\hline & FL-3-B -2-A-2.0 & & & & 11.5 & 11.29 & 0.98 \\
\hline \multirow{6}{*}{ FL-4 } & FL-4-B -1-B-0.0 & \multirow{6}{*}{4800} & \multirow{6}{*}{2400} & \multirow{6}{*}{52} & 13.3 & 13.20 & 0.99 \\
\hline & FL-4-B -1-B-0.8 & & & & 12.3 & 11.92 & 0.97 \\
\hline & FL-4-B -1-B-2.0 & & & & 11.3 & 10.02 & 0.89 \\
\hline & FL-4-B -2-B-0.0 & & & & 14.5 & 13.30 & 0.92 \\
\hline & FL-4-B -2-B-0.8 & & & & 12.4 & 13.18 & 1.06 \\
\hline & FL-4-B -2-B-2.0 & & & & 11.5 & 12.34 & 1.07 \\
\hline
\end{tabular}

Note: Thickness is the actual value of floor.

\subsection{Experiment Program}

There are two kinds of supporting conditions for composite floor: simply supported slabs (Figures 4(a) and 5(a)) and rigid supported slabs (Figures 4(b) and 5(b)).

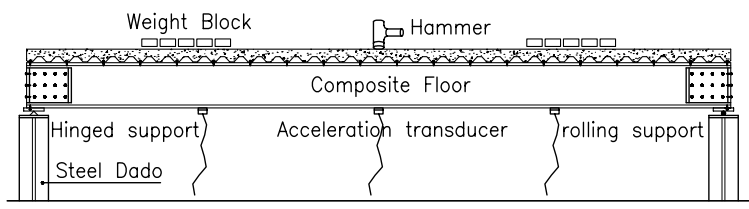

(a)

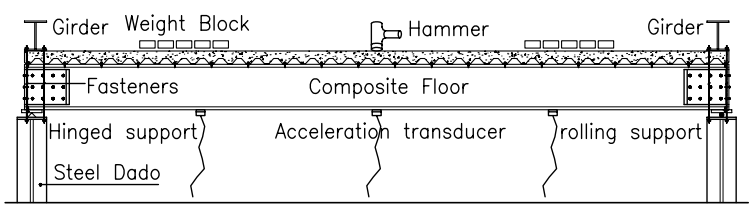

(b)

Figure 4. Test Set-up: (a) Simply Supported Slab; (b) Fix Supported Slab 

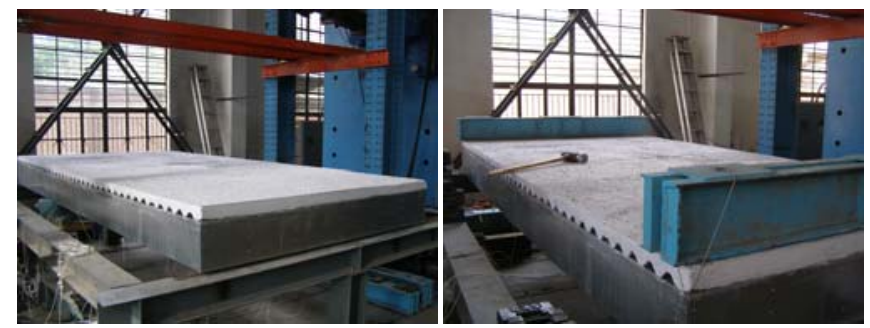

Figure 5. Constraint Condition Setup: (a) Simple Support Boundary; (b) Fixed Support Boundary

As shown in Figures 4(a) and 5(a), the hinged support is adopted in one supporting boundary, and the other is rolling support. In order to simulate the rigid support boundary, a steel beam with weight of 205kg is used on one edge of the composite floor as shown in Figures 4(b) and 5(b), and the steel beam is tightly fixed to the dado. Many weight blocks are placed on the composite floor, in order to considering the influence of live load on floor as shown in Figure 6.
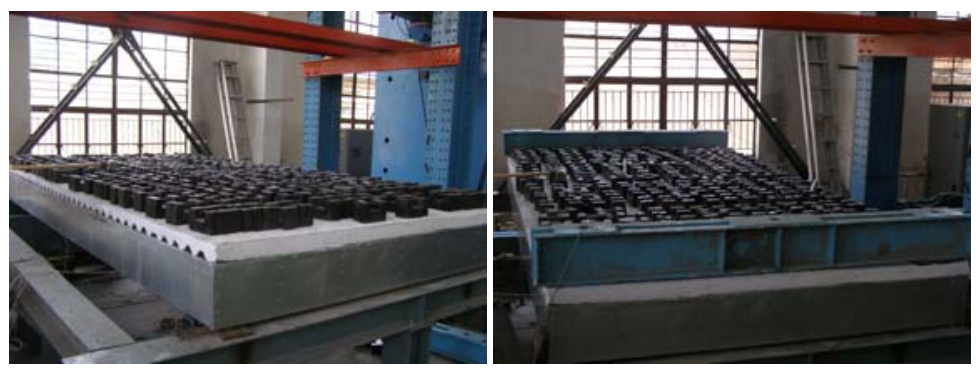

Figure 6. Weight Loading

The equipment for shock excitation is impact hammer. Many acceleration transducers are arranged on the bottom flange of the cold-formed steel joists, and they can record the dynamic response of the composite floor. All the test data were collected by LMS (Test. Lab Modal Impact) data collector. The measuring points of the acceleration transducer are shown in Figure 7. The measuring point 11 is shocking point.

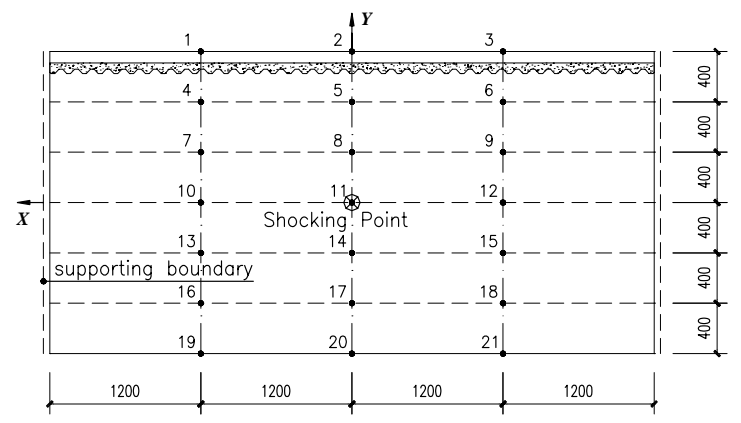

Figure 7. Layout of Measuring Points 


\subsection{Experimental Results and Analyses}

The test results of fundamental frequency in different loading conditions are listed in Table 2 . The fundamental frequencies of these given four specimens, which have the same length-width ratio but different structural mode, are more than $10 \mathrm{~Hz}$. There exist differences with the regulations in China code Technical specification for Steel Structures of Tall Buildings (JGJ99-98 [10]). However, they meet requirements that the vibration frequency of light floor should be over $8 \mathrm{~Hz}$ presented in Refs. [2-4].

The fundamental frequency comparisons of these four specimens under different loading conditions are summarized as follows.

(i) With the increase of the floor live loads, the fundamental frequency of the specimens gradually decreases in the same constraint condition. It can decay to $3 \mathrm{~Hz}$.

(ii) The bigger the screw spacings of specimens FL-3(4) are, the bigger the fundamental frequency is. The largest difference between them is $1 \mathrm{~Hz}$. The fundamental frequency of thicker profiled steel sheet and bigger joist flange screw spacing is less than that of the smaller. The FEM results show that changing screw spacing can improve flexural rigidity of composite floors, which is the same with test results in Ref. [6]. With the decreasing of screw spacing, associative effects becomes more remarkable, also the flexural rigidity and vibration frequency become larger.

The causes for larger frequency are as follows, these four composite floors are site concreting in the process of fabrication. Because of the unevenness concrete surface and the difference of thickness, the mass of these four composite floors show an uneven distribution, and the real thickness of the floor has some difference with the design. So it shows the fundamental frequency becomes larger with the screw spacing increasing.

(iii) The profiled steel sheet and joist flange screw spacing of FL-1 is the same as FL-2, just like FL-3 as FL-4. The changing of rigid boundary has little effects on the frequency increasing of the composite floors. The corresponding fundamental frequency in different working conditions is basically identical to each other. The FEM shows the fundamental frequency of the composite floors with rigid blocking is somewhat larger than that without rigid blocking. Rigid blocking can not only improve the lateral stability of the joists, but also increase the flexural rigidity of the composite floors. The rigid blocking is always assembled after the joist frame emplacement. As the small torsion stiffness of the joists with open sections can easily lead to torsion deformation, and the construction space is also small, the installation precision and fastening degree of rigid blocking are always problems in practice, which become the obstacles to fully provide the lateral supports and improve greatly the flexural rigidity of the composite floors. This paper suggests using self-tapping screws instead of self-drilling screws, and setting flat steel belts to link the bolts at the joist bottom flanges.

(iv) The fundamental frequency become higher if the end restraints are enhanced in the corresponding working conditions. It shows steel beams simulating end restraint of the wall frame stud can limit the beam-end rotation, improve flexural rigidity of the composite floor, and increase frequency. The strength of the end restraint simulated by steel beams is related to the beam mass, fastening degree between beam and pedestal, and leveling degree. Therefore the improvement of measured fundamental frequency is not obvious. 
(v) The acceleration response of the composite floors is related to energy under impact hammer effect. PSD means how the energy distributes in vibration frequency domain. The maximum of power spectrum density means the fundamental frequency of the composite floors. The acceleration and PSD in different measuring points are different, but the fundamental frequency and frequency domain are unrelated to different measuring points. The FL-1-A-1-C-0.0 measuring point distribution of PSD is showed in Figures 8 and 9. The Figures 8 and 9 include obvious peak value. Peak value always represents the fundamental frequency of the composite floors, which means most of energy concentrates in fundamental frequency limits.

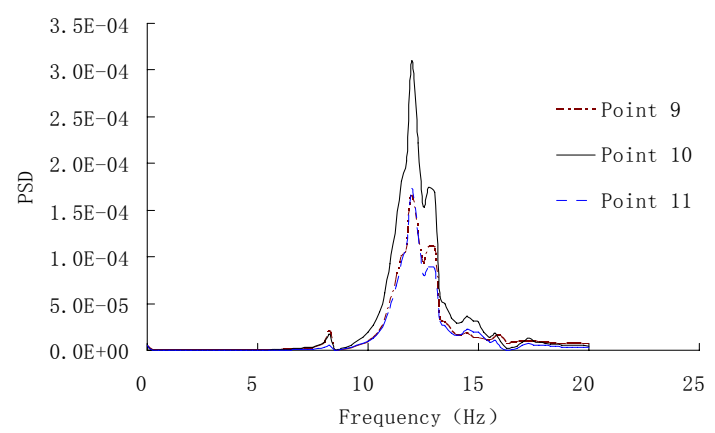

Figure 8. FL-1-A-C-0.0 along X-axis PSD

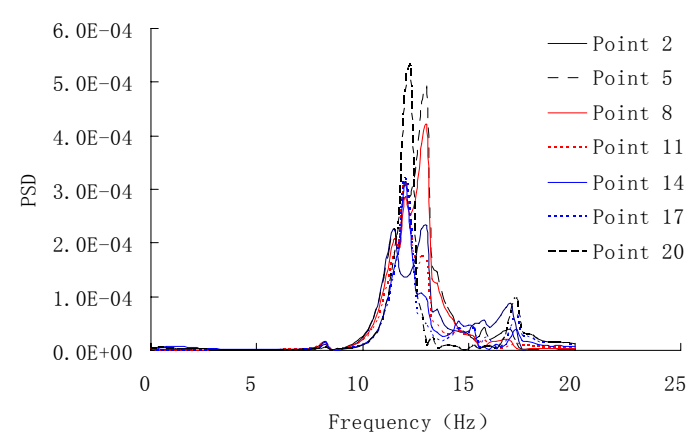

Figure 9. FL-1-A-C-0.0 along Y-axis PSD

As shown in Figure 8, the distribution value of PSD is changing with the measuring points varying. However, all the measuring points are distributed under one joist, so the PSD distribution forms are similar. Energy in point 11 is max, which gradually decreased far from impact point. The distribution value of PSD in different joists is a little different, shown in Figure 9, as the deformation of every joist is unified, when hammering on composite beams. Different structural composite beams have different PSD distribution forms and fundamental frequency, which is like FL-1-A-1-C-0.0.

In addition, we cannot feel vibration of composite floors when the author walks on the floor. However, when we hop on it we can feel a little vibration.

Former research [2 and 11] showed that, the most uncomfortable frequency of human response for residential housing stays in the range of $4-8 \mathrm{~Hz}$. And it was then provided that the fundamental frequency of the lightweight floor should be no less than $8 \mathrm{~Hz}$. However, resonance may also take place when the frequency of the pulse load is close to $10 \mathrm{~Hz}$ if the span of the floor exceeds $3 \mathrm{~m}$. Based on this, the fundamental frequency of the composite floor under standard load combination in serviceability stage should not be less than $10 \mathrm{~Hz}$, the large vibration of the floor in serviceability stage can then be avoided. Therefore, in order to avoid resonance caused by walking and jumping, this paper suggests that the controlled fundamental frequency should be more than $10 \mathrm{~Hz}$, referred to the measured results and Refs. 2-4.

\section{NUMERICAL STUDY}

In order to compare with the test results of the finished four specimens in 24 kinds of loading cases, the numerical analysis is executed for each loading case of the composite floor by finite element program ANSYS. The following assumptions are used: 
(i) Profiled steel sheets and concrete are completely bonded. The slip is not considered if there is any. The steel and concrete are considered to be elastic materials in numerical analysis.

(ii) The relative slip is allowed for the composite floor; profiled Steel Sheet-concrete composite floor and the flange of joists could impinge on the position of no screws under gravity load and live load.

(iii) The live load is converted to the equivalent density of floor board to consider its influence in the finite element analysis.

\section{1. $\quad$ Finite Element Model}

The plastic shell element SHELL181 is used to simulate the C-section joists, U-section tracks, profiled steel sheets, support stiffening members and rigid blockings, the element SOLIDE65 is used to simulate the concrete; the screws that connect the profiled steel sheets and the flanges of joists are simulated by element BEAM188. At the positions with no screws they are simulated by 3-D contact element CONTAC52; the screws among the support stiffening members, joists and tracks are simulated by coupling, the screws between rigid blocking and joist webs. When building a model, the real measured concrete thickness is used. The finite element models of composite floor are shown in Figure 10.
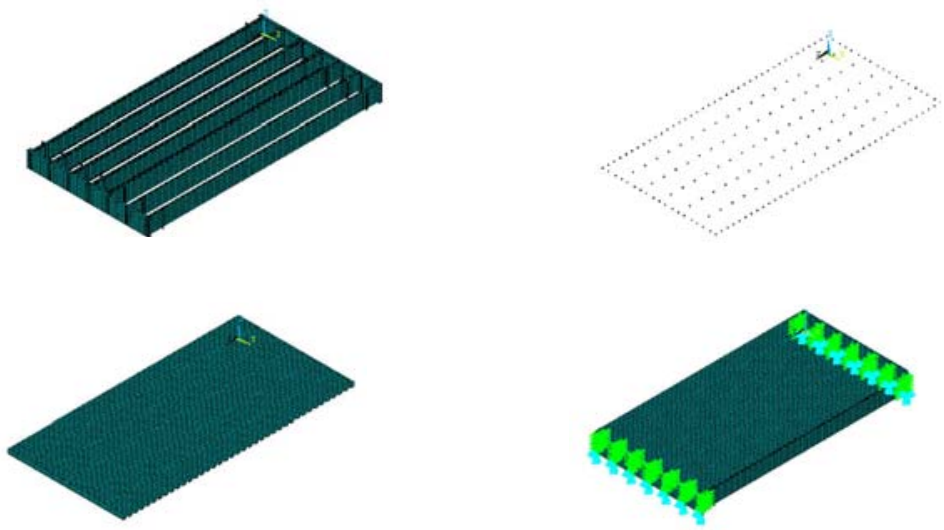

Figure 10. Finite Element Model of Composite Floor: (a) Joist; (b) Self-drilling Screw; (c) Composite Floor; (d) Coupling

\subsection{Results of Finite Element Model Analyses}

The finite model analysis is executed for four specimens under 24 kinds of loading cases by finite element program ANSYS, the fundamental frequency of numerical simulation is shown in Table 2.

The numerical simulation method used by this paper can reflect the vibration behavior of composition floor exactly, and has high precision and calculation efficiency. The calculated fundamental frequency agrees well with experimental model fundamental frequency. The results between experiment and finite element simulation have some difference under individual loading cases because of the fabrication error of the specimens, the discrimination of boundary constraint, and the fastening degree of rigid support connections. 


\section{CONCLUSIONS}

In this paper, the experimental research has been carried out for the vibration behavior of composite floor with different configuration modes, and by setting up numerical models the tested specimens have been analyzed with finite element program ANSYS. Comparison of the results from tests and finite element numerical analysis, the feasibility of precise frequency calculation by finite element program ANSYS is verified. The obtained results allow the following conclusions to be drawn.

(i) Under the same boundary constraints, the measured fundamental frequency of one specimen under different loading cases gradually decreases with the increase of floor live loads; the maximal attenuation is about $3 \mathrm{~Hz}$. The assumption that the live load is converted to the equivalent density of floor board in the finite element analysis is reasonable.

(ii) The flexural rigidity of composite floor can be improved by changing the spacing of screws. The fundamental frequency of composite floor with large spacing of the screws, that connect profiled steel sheets and the flange of joists, is smaller than the composite floor with small spacing. The lateral stability of joists can be strengthened and the flexural rigidity and frequency of composite floor will be increased by setting rigid blocking at mid-span of adjacent joist of composite floor. The fundamental frequency of composite floor is increasing if the end restraints are enhanced.

(iii) Different measuring points have different acceleration and PSD value, but the fundamental frequency and frequency domain are unrelated to different measuring points.

(iv) It is suggested that the construction quality should be strictly controlled and the fundamental frequency should be more than $10 \mathrm{~Hz}$.

\section{ACKNOWLEDGEMENTS}

This work was financially supported by the National Natural Science Foundation of China (Grant No. 50578013), College Doctor Foundation of Ministry of Education (No.20050710004), and the Fundamental Research Funds for the Central Universities of Hunan University, which are gratefully acknowledged.

\section{REFERENCES}

[1] CWC, "Development of Design Procedures for Vibrations Controlled Spans using Engineered Wood Members, Final Report Prepared for Canadian Construction Material Centre and Industry Partnership Consortium”, Canadian Wood Council, 1996.

[2] ATC, "Design Guide 1: Minimizing Floor Vibration”, Applied Technology Council Redwood, California, USA, 1999.

[3] Ohlsson, S.V., "Springiness and Human-Induced Floor Vibrations - A Design Guide - D12”, Swedish Council for Building Research, Stockholm, Sweden, 1988.

[4] AS3623, "Domestic Metal Framing Code”, Standards Association of Australia, Homebush, NSW, 1993. 
[5] Johnson, J.R., "Vibration Acceptability of Floor Under Impact Vibration”, Department of Civil Engineering, Virginia Polytechnic Institute and State University, Blacksburg, Virginia, USA, 1994.

[6] Xu, L., Tangorra, F.M., "Experimental Investigation of Lightweight Residential Floors supported by Cold-formed Steel C-shape Joists”, Journal of Constructional Steel Research, 2007, Vol. 63, No. 3, pp. 422-435.

[7] Kraus, C.A., "Floor Vibration Design Criterion for Cold-formed C-Shaped Supported Residential Floor Systems”, Virginia Polytechnic Institute and State University, Blacksburg, Virginia, USA, 1997.

[8] JG/T 182-2005, “Technical Requirements for Low-Rise Assembled Residential Buildings with Light-Weight Steel Framing”, Wanfang Data Electronic Press, China, 2005.

[9] GB 50009-2001, "Load Code for the Design of Building Structures”, China Architecture \& Building Press, Beijing, 2001.

[10] GJ 99-98, “Technical Specification for Steel Structure of Tall Buildings”, China Architecture \& Building Press, Beijing, 1998.

[11] AISC, “AISC/CISC Steel Design Guide Series 11: Floor Vibrations due to Human Activity”, Chicago, 1997. 